\title{
Upstream Therapy for Atrial Fibrillation
}

\author{
Koichiro Kumagai, MD
}

\begin{abstract}
There are multiple factors for the etiology of atrial fibrillation (AF), including stretch, autonomic imbalance, hyperthyroidism, and inflammation. Of these factors for $\mathrm{AF}$, stretch and inflammation increase the angiotensin II level, thereby inducing calcium over load, and inducing ectopic focal activities that initiate AF. Angiotensin II activates the Erk cascade through the AT $1 \mathrm{R}$ and induces interstitial fibrosis of the atria, which compromises intra-atrial conduction. Short atrial refractoriness and slow conduction form multiple re-entry, before maintaining AF. Anti-arrhythmic drugs used for downstream therapy can suppress the focal activities and re-entry, but cannot prevent the development of a structural substrate. In contrast, angiotensin-converting enzyme, angiotensin II type 1 receptor blocker and statins might constitute upstream therapy through the prevention of structural remodeling that promotes AF. (Circ J 2007; Suppl A: A-75-A-81)
\end{abstract}

Key Words: Angiotensin; Arrhythmia; Atrial fibrillation; Inflammation; Statins

$\Delta$ nti-arrhythmic drugs can suppress the ectopic focal activities and re-entrant excitations, therefore, they are usually used for the treatment of atrial fibrillation (AF). However, these drugs cannot prevent the structural substrate development. It is well known that architectural alterations of the atria, including atrial dilatation and tissue fibrosis, are associated with atrial dysfunction!, ${ }^{1,2} \mathrm{Sev}-$ eral studies have shown that activation of the renin-angiotensin system is associated with the mechanism of $\mathrm{AF}^{3-5}$ We previously reported that the blockade of angiotensin II receptors prevented the electrical and structural remodeling induced by rapid atrial pacing.6.7 Thus, an activation of the renin-angiotensin system during long-term rapid atrial excitation participates in the mechanisms of AF maintenance through the creation of structural abnormalities.

\section{Possible Mechanisms of AF Promotion}

Previous studies have shown that shortened atrial effective refractory period (AERP) and loss of its adaptation to rate, which have been referred to as electrical remodeling, are observed in the pacing-induced AF model?-10 Wijffels et al reported the AERP shortening and increased vulnerability to $\mathrm{AF}$ in the goat model ${ }^{11}$ However, there was a discrepancy in the time-course between these 2 changes. AERP shortening began within $24 \mathrm{~h}$, whereas it took longer than a week for the induced AF to stabilize. These results indicated that a decreased wavelength, which is caused by a shortened AERP and decreased conduction velocity, might play a critical role in the development of chronic AF. Moreover, Everett et al demonstrated that a shortened AERP returned to the baseline level in 7-14 days after 6 weeks of rapid atrial pacing!2 Despite the complete normalization of AERP, the structural abnormalities of the atria persisted. Based on these results, not only AERP shortening but also

(Received December 16, 2006; revised manuscript received December 28, 2006; accepted January 9, 2007)

Department of Cardiology, School of Medicine, Fukuoka University, Fukuoka, Japan

Mailing address: Koichiro Kumagai, MD, Department of Cardiology, School of Medicine, Fukuoka University, 7-45-1 Nanakuma, Jonan-ku,

Fukuoka 814-0180, Japan. E-mail: kxk@fukuoka-u.ac.jp other additional factors, including conduction and structural abnormalities of the atria, might be involved in the promotion of $\mathrm{AF}$.

Therefore, we investigated the effects of an angiotensin II type 1 receptor blocker (ARB), candesartan, on the longterm structural remodeling in a canine model of rapid pacing-induced AF? Although the degree of the shortening of AERP was similar between the candesartan group and controls, treatment with candesartan significantly decreased the conduction delay by suppressing interstitial fibrosis. These results indicate that angiotensin II might be involved in the mechanism of structural remodeling in chronic $\mathrm{AF}$, and might lead to therapies to prevent both electrical and structural substrate development. In this study, AERP was significantly shortened in the first week, and there was no further shortening of AERP at the later period. In contrast, the intra-atrial conduction time was gradually and progressively prolonged up to 5 -week pacing. Furthermore, the inducibility of $\mathrm{AF}$ and its mean duration was increased significantly from the first week to the fourth and fifth weeks in parallel with the intra-atrial conduction slowing. These findings indicate that conduction slowing might contribute to the initiation and maintenance of AF.

\section{Role of the Renin-Angiotensin System on Electrical Remodeling}

Previous studies have shown that atrial tachycardia-induced electrical remodeling, which is composed of AERP shortening and loss of physiological rate adaptation, is responsible for the increase of AF inducibility and stability $1-4$ The intracellular calcium overload during high-frequency atrial activation is supposed to contribute to this phenomenon of electrical remodeling9,10,13,14 Accordingly, a L-type calcium channel blocker, verapamil, has been suggested to prevent short-term electrical remodeling in animal and human studies?,10,13,14 However, several studies have demonstrated that verapamil does not prevent AERP shortening and loss of its rate adaptation following AF induced by long-term tachycardia, and that verapamil increases the duration of $\mathrm{AF}$ induced ${ }^{15-18}$ We reported previously that verapamil increased intra-atrial conduction delay and frag- 

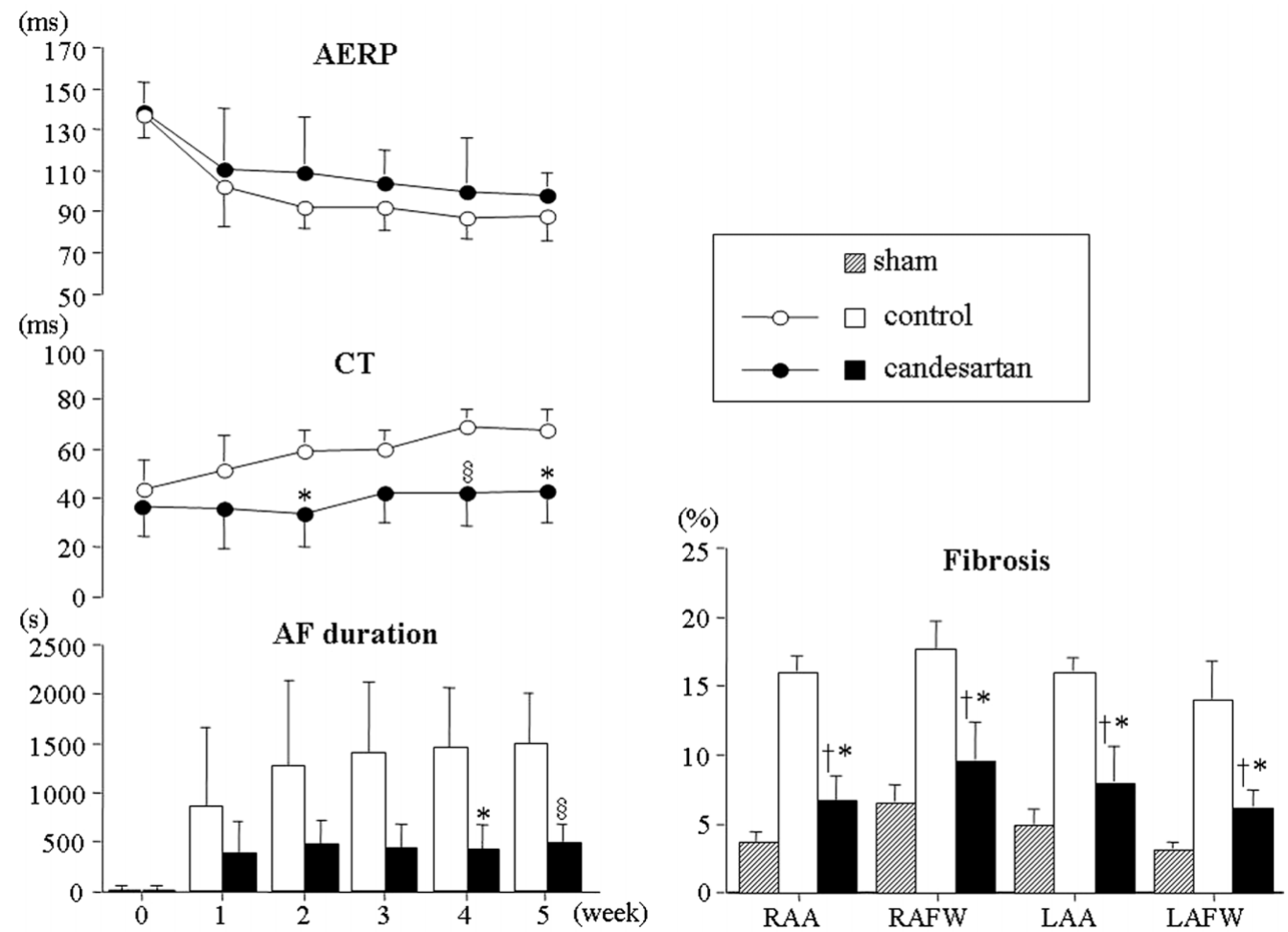

Fig 1. Effects of angiotensin II type 1 receptor blocker on atrial remodeling in a canine model of rapid pacing-induced atrial fibrillation (AF). Time-course of the percent changes in the atrial effective refractory period (AERP) of the right atrial appendage and intra-atrial conduction time (CT) from the right atrial appendage to the lower right atrial wall at a basic cycle length of $300 \mathrm{~ms}$, and the mean duration of induced AF in the control and candesartan groups. The degree of AERP shortening was similar between the 2 groups; the intra-atrial CT in the candesartan group was significantly shorter than that in the control group, and the mean AF duration in the candesartan group was significantly shorter than that in the control group. The percentage of fibrosis of the free walls and appendages in both atria after 5 weeks of pacing was shown. The percentage of fibrosis in all atrial regions in the candesartan group was markedly lower than that in the control, although greater than that in the sham group. ${ }^{\dagger} \mathrm{p}<0.001$ compared with the control group. ${ }^{*} \mathrm{p}<0.05$ compared with the sham group. RAA, right atrial appendage; RAFW, right atrial free wall; LAA, left atrial appendage; LAFW, left atrial free wall (Reproduced from J Am Coll Cardiol 2003; 41: 2197-2204, with permission). ${ }^{\S} \mathrm{p}<0.01,{ }^{*} \mathrm{p}<0.05$ compared with the control group.

mented activity in patients with paroxysmal AF!9 These results suggested that intracellular calcium overload might contribute to a mechanism of electrical remodeling only in the short-term, but not in the long-term. Shinagawa et al found that amiodarone prevented tachycardia-induced atrial electrical remodeling in a dog model, in terms of both atrial electrical properties and ion-channel subunit expression. ${ }^{20}$ Because amiodarone can share $\mathrm{T}$-type $\mathrm{Ca}^{2+}$-channel-inhibiting actions, it is tempting to speculate that the T-type blockade plays a central role.

We previously reported that the angiotensin convertingenzyme inhibitor (ACEI) and ARB prevented AERP shortening in a canine short-term rapid pacing model 6 The beneficial effects of these drugs might be ascribed, in part, to a reduction of atrial stretch in response to rapid atrial activation. We also examined the effects of an ARB, candesartan, on the long-term atrial electrical remodeling. Candesartan did not prevent AERP shortening after 1 week of rapid pacing, suggesting that long-term electrical remodeling cannot be explained solely by calcium overload (Fig 1). Shinagawa et al also reported that the ACEI, enalapril, did not prevent AERP shortening after 7 days of rapid pacing, suggesting apparent differences in the pathogenesis of short-term and long-term remodeling. ${ }^{21}$ They suggested that short-term remodeling is primarily caused by functional changes such as $\mathrm{Cai}^{2+-}$ and voltage-dependent ICaL inactivation, whereas long-term remodeling is caused by changes in ion channel expression at transcriptional and/or post-transcriptional levels. This might explain why candesartan inhibited the short-term electrical remodeling, but not the long-term electrical remodeling. However, candesartan significantly decreased the inducibility and the duration of AF after 5 weeks of rapid atrial pacing, probably by preventing the development of conduction slowing (Fig 1). Therefore, the blockade of angiotensin II might attenuate the arrhythmogenic substrate, which might promote the transition to chronic AF.

\section{Role of the Renin-Angiotensin System on Structural Remodeling}

$\mathrm{AF}$ is associated with progressive structural changes of the atria, resulting in atrial dilatation and increased interstitial fibrosis!,12 $\mathrm{Li}$ et al reported that decreased AERP and increased AERP heterogeneity were not observed in a dog model of heart failure, while AF inducibility and duration were significantly increased compared to those in control dogs? Local conduction slowing, its heterogeneity, and the interstitial fibrosis of the atria were prominent in dogs with heart failure. Therefore, the changes in local atrial conduc- 
A Sham

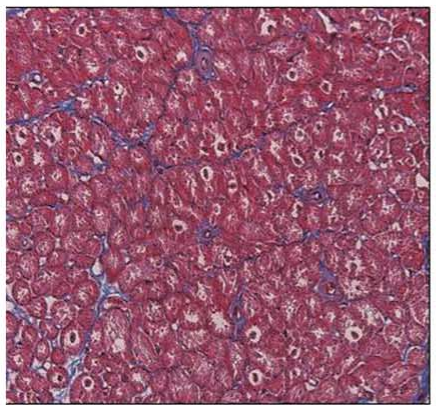

B Control

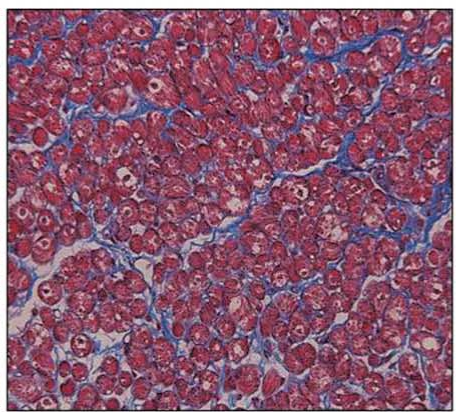

C Candesartan

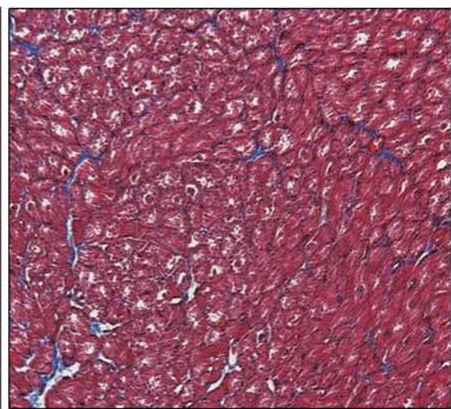

Fig 2. Effects of angiotensin II type 1 receptor blocker on atrial remodeling in a canine model of rapid pacing-induced atrial fibrillation. Representative histological sections of the right atrial free wall from each group (Masson trichrome stain) from a sham dog (A), a fifth week rapid pacing dog (B), and a fifth week rapid pacing with a candesartan-treated dog (C). In a sham dog, the intracellular space appeared normal. In a control dog, extensive interstitial fibrosis, evidenced by Masson trichrome stain, was found. In a candesartan-treated dog, interstitial fibrosis was attenuated (Reproduced from $J$ Am Coll Cardiol 2003; 41: 2197-2204, with permission). Magnification: $\times 400$.
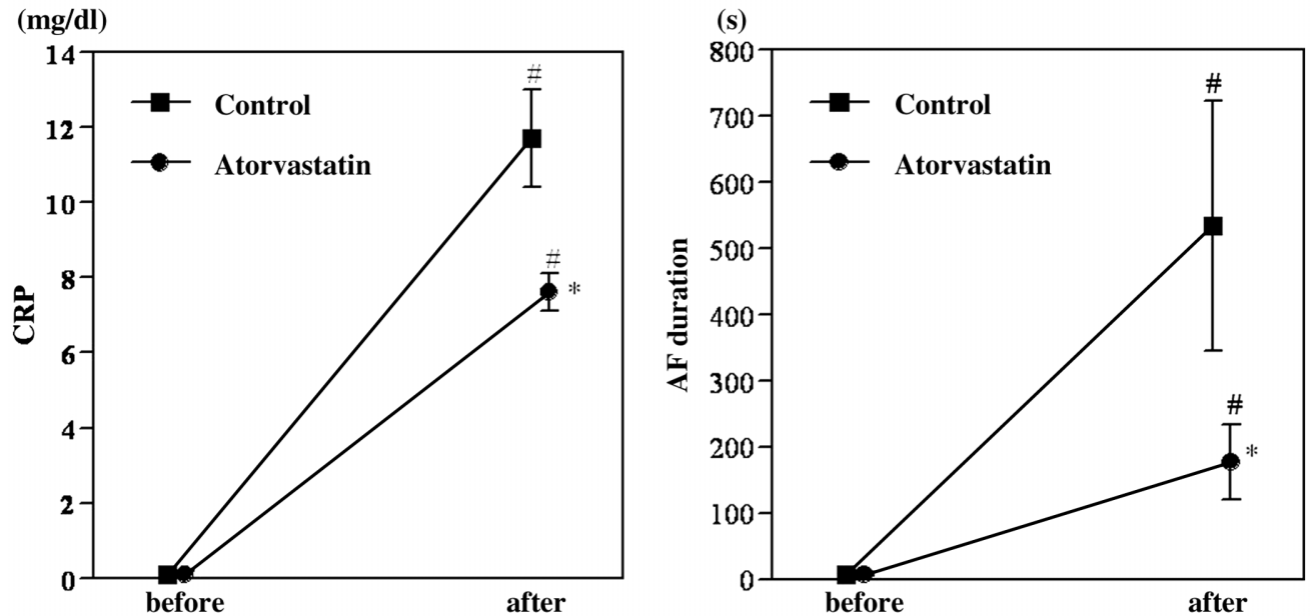

Fig 3. Effects of statin on atrial fibrillation (AF) in a canine sterile pericarditis model. Left: Comparison of C-reactive protein (CRP) levels between the control and atorvastatin groups before and after operation. Before the operation, there were no significant differences in the CRP levels between 2 groups. On the second postoperative day, the CRP was significantly increased in both groups; however, it was significantly lower in the atorvastatin group than in the control. ${ }^{\#} \mathrm{p}<0.0001$ compared with before the operation. ${ }^{*} \mathrm{p}<0.0001$ compared with the control group. Right: Comparison of the duration of induced atrial fibrillation between the control and atorvastatin groups before and after operation. Before the operation, there were no significant differences in atrial fibrillation duration between 2 groups. On the second postoperative day, the atorvastatin group had a shorter atrial fibrillation duration than the control (Reproduced from Cardiovasc Res 2004; 62: $105-111$, with permission). ${ }^{*} \mathrm{p}<0.0001$ compared with before the operation. ${ }^{*} \mathrm{p}<0.0001$ compared with the control group.

tion properties caused by interstitial fibrosis favor the maintenance of $\mathrm{AF}$ in dogs with heart failure.

Recently, Goette et al demonstrated that the expression of angiotensin converting-enzyme and Erk1/Erk2 was enhanced in patients with $\mathrm{AF}^{3}$. Willems et al established that the development of AF by rapid pacing was associated with an increase in the plasma level of angiotensin II in a sheep model.22 In animal studies, it has been reported that high atrial pressure directly caused AERP shortening and increased AERP dispersion, resulting in increased vulnerability to $\mathrm{AF}^{23-25}$ In addition to these direct effects on electrophysiological properties, increased atrial stretching activates the Erk cascade through the AT1R, which might induce interstitial fibrosis of the atria?,26 More interestingly, treatment with ACEI decreased the level of an activated Erk1/Erk2? ARB might also have similar inhibitory effects on these kinases, resulting in decreasing atrial fibrosis (Figs 2,3). The inhibition of local angiotensin II can prevent the promotion of AF by suppressing the development of the structural substrate. In addition, ARB has been reported to decrease atrial pressure ${ }^{27}$ Therefore, it is possible that a decrease in atrial stretching by ARB might directly precipitate electrophysiological changes to prevent AF.

\section{Role of Inflammation on AF}

Structural changes in the atria in association with inflammation might promote AF persistence. Recently, Chung et al reported that C-reactive protein (CRP) was elevated in patients with $\mathrm{AF}$ and was higher in patients with persistent $\mathrm{AF}$ compared to those with paroxysmal $\mathrm{AF}^{28}$

Evidence for an inflammatory contribution to at least 


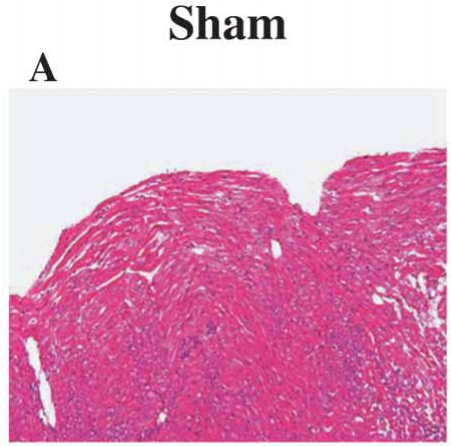

D

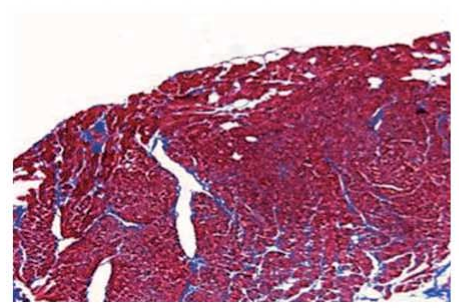

Control

B

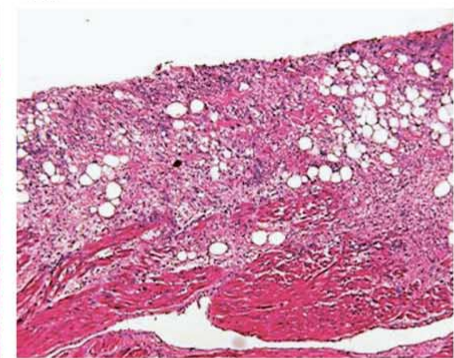

E

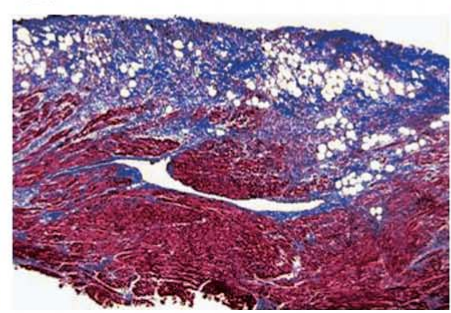

Atorvastatin

C

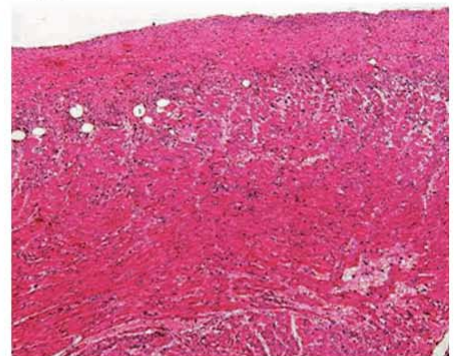

F

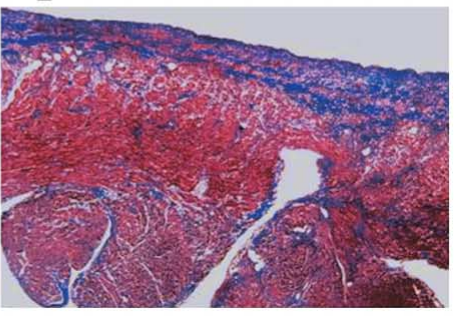

Fig 4. Effects of statin on atrial fibrillation in a canine sterile pericarditis model. Representative histological sections of the right atrial free wall from each group were taken. (A) A sham dog sample stained with haematoxylin-eosin, (B) a control dog sample stained with haematoxylin-eosin, (C) an atorvastatin-treated dog sample stained with haematoxylineosin, (D) a sham dog sample stained with Masson trichrome, (E) a control dog sample stained with Masson trichrome, and $(F)$ an atorvastatin-treated dog sample stained with Masson trichrome. In a sham dog, the intracellular space appeared normal. In a control dog, active perimyocarditis was found, which consisted of inflammatory infiltrate with lipid degeneration, was confined to the atrial myocardium and extensive interstitial fibrosis, evidenced by Masson trichrome stain. In contrast, these pathological abnormalities of atrial tissues were attenuated in an atorvastatin dog (Reproduced from Cardiovasc Res 2004; 62: 105-111, with permission). Magnification: $\times 400$.

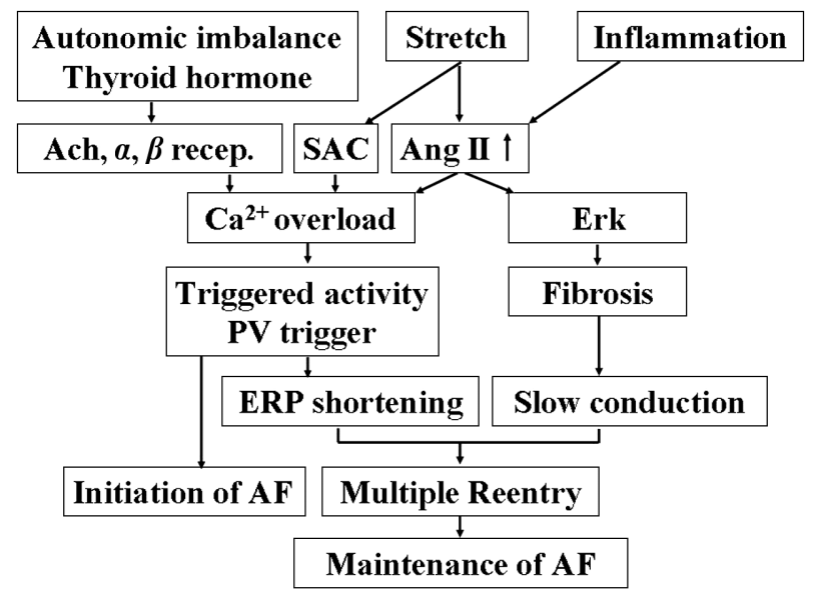

Fig 5. Mechanism of promotion of atrial fibrillation (AF). Ach, acetylcholine; Ang II, angiotensin II; SAC, stretch activated channel; PV, pulmonary vein; ERP, effective refractory period; Erk, extracellular signal-regulated kinase.

some forms of AF was initially suggested by the high incidences $(25-40 \%)$ of AF after cardiac surgery. Activation of the complement system and release of proinflammatory cytokines occur after cardiac surgery, suggesting the presence of an intense inflammatory process. The production of CRP, a prototypic marker of inflammation, is driven by the proinflammatory cytokines interleukin (IL)-1, tumor necrosis factora, and IL-6 $6{ }^{2}$ Bruins et al reported that IL-6 levels rise markedly, peaking $6 \mathrm{~h}$ after surgery $30 \mathrm{~A}$ second peak of CRP elevation comes on the second postoperative day, and the complement-CRP complexes peak on the second or third postoperative day. The incidence of atrial arrhythmias similarly peaks $2-3$ days after surgery. It was demonstrated by Page et al in a canine sterile pericarditis model that the peak of $\mathrm{AF}$ induction comes on the second postoperative day ${ }^{31}$ Mapping studies during AF in the sterile pericarditis model have shown that multiple unstable re-entrant circuits are critical for maintaining $\mathrm{AF}^{32}$ In this model, we have demonstrated that elevated CRP was associated with sustained $\mathrm{AF}^{33}$

Atrial structural remodeling might occur from inflammatory stressors. The anatomic substrate of electrical atrial instability has been investigated in vivo using both surgical and atrial biopsy approaches. Basso et al reported a 50\% incidence of isolated atrial myocarditis in fatal WolffParkinson-White cases 34 This finding supports the hypothesis that atrial inflammatory foci might act as a trigger of paroxysmal AF. Notably, the possibility of an isolated arrhythmogenic atrial myocarditis was put forward by Fromer et $\mathrm{al}^{35}$ who studied 2 cases of drug-refractory ectopic atrial tachycardia; surgically resected tissue showed focal myocarditis at endomyocardial biopsy being associated with a minor elevation of antibodies against echovirus in 1 case. In the canine pericarditis model, we showed that active perimyocarditis, which consisted of patchy inflammatory infiltrate with lipid degeneration, occurred in dogs with sustained AF and was confined to the atrial myocardium $3^{3}$ Thus, inflammatory changes might contribute to atrial structural remodeling and increase the propensity for $\mathrm{AF}$ to persist. 


\section{Statin and AF}

It is conceivable that the prevention of AF with elevated CRP might be improved by using anti-inflammatory agents or other CRP-lowering drugs. Recent studies have shown that it is possible to modulate CRP levels with pharmacological interventions, including HMG-CoA reductase inhibitor (statin) drugs ${ }^{36-38}$ Statin reduces cardiovascular risk, the mechanism of which might include diminished arterial inflammation, as suggested by a reduction in levels of CRP in serum that appear to be independent of a reduction in lowdensity lipoprotein-cholesterol levels. 39,40 Thus, modalities targeting inflammation and reducing proinflammatory cytokines and CRP levels could be a potential additional strategy in the prevention of cardiovascular disease. Ridker et $\mathrm{al}^{41}$ demonstrated that patients who have increased CRP levels (increased inflammation) gain a greater benefit from pravastatin therapy ${ }^{41}$ and that median CRP levels were reduced to $17.4 \%$ in the group that received pravastatin ${ }^{36}$ Furthermore, Jialal et al showed that treatment with atorvastatin also results in a significant reduction in CRP levels (mean percent reduction in CRP levels: $28.3 \%)^{40}$ Therefore, it is conceivable that the prevention of AF with elevated CRP might be improved by the use of statins. We documented that atorvastatin prevented the promotion of atrial electrophysiological and structural changes resulting from inflammation in the canine sterile pericarditis model (Figs 3,4) ${ }^{3}$ Thus, atorvastatin could attenuate the substrate of AF by inhibiting inflammation.

Although we proved that atorvastatin did prevent the maintenance of AF in the canine sterile pericarditis model, these results could not be extrapolated to other animal AF models or non-postoperative AF patients. However, Chung et al demonstrated that CRP was also elevated in patients with lone $\mathrm{AF}$ in the absence of structural heart disease when compared with the control subjects. ${ }^{28}$ Moreover, inflammatory changes have also been reported in patients with nonpostoperative AF. In a series of 12 patients with drugrefractory paroxysmal AF, which was studied by using an atrial endomyocardial biopsy, Frustaci et al found isolated atrial lymphocytic myocarditis in $66 \%$ of the cases ${ }^{42}$ The cause-effect relationship between myocarditis and AF was further supported by the absence of AF recurrence in patients treated with steroids. Thus, recent data suggest that in a certain population of patients with lone paroxysmal AF, this could be caused by isolated atrial myocarditis. Therefore, anti-inflammatory agents or CRP-lowering drugs such as statins might improve the prevention of AF.

The pleiotropic effects of statins might be largely mediated by nitric oxide ${ }^{4} 3$ which can induce cardioprotection. It has been demonstrated that statins can attenuate oxidantinduced mitochondrial dysfunction in cardiac myocites 44 and downregulate the activity of small G proteins in cardiomyocytes and, therefore, influence surrogate markers of cardiac dysfunction such as the atrial natriuretic factor and myosin light chain-245 These additional effects of statins might be involved in their antiarrhythmic activity. However, it has been reported that pacing-induced AERP shortening and $\mathrm{AF}$ promotion were unaffected by vitamin $\mathrm{C}$ or vitamins $\mathrm{C}$ and $\mathrm{E}$ in a dog model ${ }^{46}$ In addition, the result of a recent clinical study has shown that the use of statins in patients with lone $\mathrm{AF}$ was associated with a decrease in the recurrence of AF after successful cardioversion. ${ }^{47}$ Thus, statins might constitute a novel therapeutic approach for the prevention of AF.

\section{Clinical Evidences}

$\mathrm{AF}$ is a common arrhythmia in patients with heart failure, and we often experience difficulties in controlling druginduced negative inotropic and proarrhythmic effects, especially in patients with left ventricular dysfunction. Recent clinical trials have reported that ACEI and ARB reduce the incidence of new-onset AF in patients with left ventricular dysfunction and congestive heart failure $5,48-52$ In addition to this suppression of new-onset AF, the AFFIRM study demonstrated that ACEI treatment suppresses AF relapse in patients with congestive heart failure who had been randomized to rhythm control53 ${ }^{3}$ Van Den Berg et al showed that an ACEI, lisinopril, decreased the recurrence of AF after cardioversion in patients with congestive heart failure ${ }^{4}$ Furthermore, Madrid et al reported that patients who had been treated with amiodarone plus the ARB, irbesartan, had a lower rate of AF recurrence after electrical cardioversion of persistent AF ( $>7$ days) compared with the patients treated with amiodarone alone 55 Ueng et al also demonstrated that the addition of the ACEI, enalapril, to amiodarone decreased AF relapse after cardioversion in patients with persistent $\mathrm{AF}$ ( $>3$ months) ${ }^{56}$ Zaman et al showed that long-term ACEI therapy significantly decreased the duration of signal-averaged P-wave 1 year after successful electrical cardioversion in patients with persistent AF, which suggests amelioration of the arrhythmogenic substrate 57 Based on these results, angiotensin II inhibition might help reverse the AF-induced arrhythmogenic remodeling in favor of subsequent long-term maintenance of sinus rhythm after cardioversion of persistent AF. These previous clinical trials demonstrated that treatment with an ACEI or ARB had beneficial effects in AF patients with cardiac risk factors: $5,48-52,57$

\section{Upstream Therapy for AF}

In Fig 5, the mechanism of promotion of AF is summarized. There are multiple factors for etiology of AF, including stretch, autonomic imbalance, hyperthyroidism, and inflammation. Of several factors for AF, stretch and inflammation increase the angiotensin II level, which induces calcium over load and a triggered activity, before initiating AF. Whereas angiotensin II activates the Erk cascade through the AT1R, inducing interstitial fibrosis of the atria, before promoting slow conduction. Short atrial refractoriness and slow conduction set a stage for multiple re-entry, before maintaining AF. Antiarrhythmic drugs, which are considered downstream therapy, can suppress the ectopic focal activities and re-entrant excitations, but cannot prevent the structural substrate development. In contrast, ACEI and ARB can prevent the promotion of AF by suppressing the development of structural remodeling, and therefore, might constitute an upstream therapy for preventing AF promotion.

\section{References}

1. Ausma J, Wijffels M, Thone F, Wouters L, Allessie M, Borgers M. Structural changes of atrial myocardium due to sustained atrial fibrillation in the goat. Circulation 1997; 96: 3157-3163.

2. Li D, Fareh S, Leung TK, Nattel S. Promotion of atrial fibrillation by heart failure in dogs: Atrial remodeling of a different sort. Circulation 1999; 100: 87-95.

3. Goette A, Staack T, Rocken C, Arndt M, Geller JC, Huth C, et al. Increased expression of extracellular signal-regulated kinase and angiotensin-converting enzyme in human atria during atrial fibrilla- 
tion. J Am Coll Cardiol 2000; 35: 1669-1677.

4. Goette A, Arndt M, Rocken C, Spiess A, Staack T, Geller JC, et al. Regulation of angiotensin II receptor subtypes during atrial fibrillation in humans. Circulation 2000; 101: 2678-2681.

5. Pedersen OD, Bagger H, Kober L, Torp-Pedersen C. Trandolapril reduces the incidence of atrial fibrillation after acute myocardial infarction in patients with left ventricular dysfunction. Circulation 1999; 100: $376-380$

6. Nakashima H, Kumagai K, Urata H, Gondo N, Ideishi M, Arakawa $\mathrm{K}$. Angiotensin II antagonist prevents electrical remodeling in atrial fibrillation. Circulation 2000; 101: 2612-2617.

7. Kumagai K, Nakashima H, Urata H, Gondo N, Arakawa K, Saku K. Effects of angiotensin II type 1 receptor antagonist on electrical and structural remodeling in atrial fibrillation. J Am Coll Cardiol 2003; 41: $2197-2204$

8. Wijffels MC, Kirchhof CJ, Dorland R, Allessie MA. Atrial fibrillation begets atrial fibrillation: A study in awake chronically instrumented goats. Circulation 1995; 92: 1954-1968.

9. Goette A, Honeycutt C, Langberg JJ. Electrical remodeling in atrial fibrillation: Time course and mechanisms. Circulation 1996; 94: $2968-2974$

10. Tieleman RG, De Langen C, Van Gelder IC, de Kam PJ, Grandjean $\mathrm{J}, \mathrm{Bel} \mathrm{KJ}$, et al. Verapamil reduces tachycardia-induced electrical remodeling of the atria. Circulation 1997; 95: 1945-1953.

11. Wijffels MC, Kirchhof CJ, Dorland R, Power J, Allessie MA. Electrical remodeling due to atrial fibrillation in chronically instrumented conscious goats: Roles of neurohumoral changes, ischemia, atrial stretch, and high rate of electrical activation. Circulation 1997; 96: $3710-3720$

12. Everett THt, Li H, Mangrum JM, McRury ID, Mitchell MA, Redick JA, et al. Electrical, morphological, and ultrastructural remodeling and reverse remodeling in a canine model of chronic atrial fibrillation. Circulation 2000; 102: 1454-1460.

13. Tieleman RG, Van Gelder IC, Crijns HJ, De Kam PJ, Van Den Berg MP, Haaksma J, et al. Early recurrences of atrial fibrillation after electrical cardioversion: A result of fibrillation-induced electrical remodeling of the atria? J Am Coll Cardiol 1998; 31: 167-173.

14. Daoud EG, Knight BP, Weiss R, Bahu M, Paladino W, Goyal R, et al. Effect of verapamil and procainamide on atrial fibrillation-induced electrical remodeling in humans. Circulation 1997; 96: 1542-1550.

15. Shenasa M, Kus T, Fromer M, LeBlanc RA, Dubuc M, Nadeau R. Effect of intravenous and oral calcium antagonists (diltiazem and verapamil) on sustenance of atrial fibrillation. Am J Cardiol 1988; 62: $403-407$.

16. Lee SH, Yu WC, Cheng JJ, Hung CR, Ding YA, Chang MS, et al. Effect of verapamil on long-term tachycardia-induced atrial electrical remodeling. Circulation 2000; 101: 200-206.

17. Fareh S, Benardeau A, Thibault B, Nattel S. The T-type $\mathrm{Ca}(2+)$ channel blocker mibefradil prevents the development of a substrate for atrial fibrillation by tachycardia-induced atrial remodeling in dogs. Circulation 1999; 100: 2191-2197.

18. Ramanna H, Elvan A, Wittkampf FH, de Bakker JM, Hauer RN, Robles de Medina EO. Increased dispersion and shortened refractoriness caused by verapamil in chronic atrial fibrillation. $J$ Am Coll Cardiol 2001; 37: 1403-1407.

19. Kumagai K, Matsuo K, Ono M, Yamanouchi Y, Moroe K, Hamasaki $\mathrm{N}$, et al. Effects of verapamil on electrophysiological properties in paroxysmal atrial fibrillation. Pacing Clin Electrophysiol 1993; 16: 309-316.

20. Shinagawa K, Shiroshita-Takeshita A, Schram G, Nattel S. Effects of antiarrhythmic drugs on fibrillation in the remodeled atrium: Insights into the mechanism of the superior efficacy of amiodarone. Circulation 2003; 107: 1440-1446.

21. Shinagawa K, Mitamura H, Ogawa S, Nattel S. Effects of inhibiting $\mathrm{Na}(+) / \mathrm{H}(+)$-exchange or angiotensin converting enzyme on atrial tachycardia-induced remodeling. Cardiovasc Res 2002; 54: $438-$ 446.

22. Willems R, Sipido KR, Holemans P, Ector H, Van de Werf F, Heidbuchel H. Different patterns of angiotensin II and atrial natriuretic peptide secretion in a sheep model of atrial fibrillation. J Cardiovasc Electrophysiol 2001; 12: 1387-1392.

23. Sideris DA, Toumanidis ST, Tselepatiotis E, Kostopoulos K, Stringli $\mathrm{T}$, Kitsiou T, et al. Atrial pressure and experimental atrial fibrillation. Pacing Clin Electrophysiol 1995; 18: 1679-1685.

24. Satoh T, Zipes DP. Unequal atrial stretch in dogs increases dispersion of refractoriness conducive to developing atrial fibrillation. $J$ Cardiovasc Electrophysiol 1996; 7: 833-842.

25. Ravelli F, Allessie M. Effects of atrial dilatation on refractory period and vulnerability to atrial fibrillation in the isolated Langendorffperfused rabbit heart. Circulation 1997; 96: 1686-1695.
26. Kijima K, Matsubara H, Murasawa S, Maruyama K, Mori Y, Ohkubo N, et al. Mechanical stretch induces enhanced expression of angiotensin II receptor subtypes in neonatal rat cardiac myocytes. Circ Res 1996; 79: 887-897.

27. Gottlieb SS, Dickstein K, Fleck E, Kostis J, Levine TB, LeJemtel T, et al. Hemodynamic and neurohormonal effects of the angiotensin II antagonist losartan in patients with congestive heart failure. Circulation 1993; 88: $1602-1609$.

28. Chung MK, Martin DO, Sprecher D, Wazni O, Kanderian A, Carnes CA, et al. C-reactive protein elevation in patients with atrial arrhythmias: Inflammatory mechanisms and persistence of atrial fibrillation. Circulation 2001; 104: 2886-2891.

29. Gabay C, Kushner I. Acute-phase proteins and other systemic responses to inflammation. N Engl J Med 1999; 340: 448-454.

30. Bruins P, te Velthuis H, Yazdanbakhsh AP, Jansen PG, van Hardevelt FW, de Beaumont EM, et al. Activation of the complement system during and after cardiopulmonary bypass surgery: Postsurgery activation involves $\mathrm{C}$-reactive protein and is associated with postoperative arrhythmia. Circulation 1997; 96: 3542-3548.

31. Page PL, Plumb VJ, Okumura K, Waldo AL. A new animal model of atrial flutter. J Am Coll Cardiol 1986; 8: 872-879.

32. Kumagai K, Khrestian C, Waldo AL. Simultaneous multisite mapping studies during induced atrial fibrillation in the sterile pericarditis model: Insights into the mechanism of its maintenance. Circulation 1997; 95: 511-521.

33. Kumagai K, Nakashima H, Saku K. The HMG-CoA reductase inhibitor atorvastatin prevents atrial fibrillation by inhibiting inflammation in a canine sterile pericarditis model. Cardiovasc Res 2004; 62: 105111.

34. Basso C, Corrado D, Rossi L, Thiene G. Ventricular preexcitation in children and young adults: Atrial myocarditis as a possible trigger of sudden death. Circulation 2001; 103: 269-275.

35. Fromer M, Genton C, Schlaepfer J, Goy JJ, Kappenberger L. Is there an isolated arrhythmogenic right atrial myocarditis? Eur Heart J 1990; 11: 566-571.

36. Ridker PM, Rifai N, Pfeffer MA, Sacks F, Braunwald E. Long-term effects of pravastatin on plasma concentration of C-reactive protein: The Cholesterol and Recurrent Events (CARE) Investigators. Circulation 1999; 100: 230-235.

37. Ridker PM, Rifai N, Lowenthal SP. Rapid reduction in C-reactive protein with cerivastatin among 785 patients with primary hypercholesterolemia. Circulation 2001; 103: 1191-1193.

38. Strandberg TE, Vanhanen H, Tikkanen MJ. Effect of statins on Creactive protein in patients with coronary artery disease. Lancet 1999; 353: 118-119.

39. Ridker PM, Rifai N, Clearfield M, Downs JR, Weis SE, Miles JS, et al. Measurement of C-reactive protein for the targeting of statin therapy in the primary prevention of acute coronary events. $N$ Engl J Med 2001; 344: 1959-1965.

40. Jialal I, Stein D, Balis D, Grundy SM, Adams-Huet B, Devaraj S. Effect of hydroxymethyl glutaryl coenzyme a reductase inhibitor therapy on high sensitive C-reactive protein levels. Circulation 2001; 103: $1933-1935$.

41. Ridker PM, Rifai N, Pfeffer MA, Sacks FM, Moye LA, Goldman S, et al. Inflammation, pravastatin, and the risk of coronary events after myocardial infarction in patients with average cholesterol levels: Cholesterol and Recurrent Events (CARE) Investigators. Circulation 1998; 98: 839-844.

42. Frustaci A, Chimenti C, Bellocci F, Morgante E, Russo MA, Maseri A. Histological substrate of atrial biopsies in patients with lone atrial fibrillation. Circulation 1997; 96: 1180-1184.

43. Lefer AM, Scalia R, Lefer DJ. Vascular effects of HMG CoA-reductase inhibitors (statins) unrelated to cholesterol lowering: New concepts for cardiovascular disease. Cardiovasc Res 2001; 49: $281-$ 287.

44. Jones SP, Teshima Y, Akao M, Marban E. Simvastatin attenuates oxidant-induced mitochondrial dysfunction in cardiac myocytes. Circ Res 2003; 93: 697-699.

45. Laufs U, Kilter H, Konkol C, Wassmann S, Bohm M, Nickenig G. Impact of HMG CoA reductase inhibition on small GTPases in the heart. Cardiovasc Res 2002; 53: 911-920.

46. Shiroshita-Takeshita A, Schram G, Lavoie J, Nattel S. Effect of simvastatin and antioxidant vitamins on atrial fibrillation promotion by atrial-tachycardia remodeling in dogs. Circulation 2004; 110: $2313-2319$.

47. Siu CW, Lau CP, Tse HF. Prevention of atrial fibrillation recurrence by statin therapy in patients with lone atrial fibrillation after successful cardioversion. Am J Cardiol 2003; 92: 1343-1345.

48. The CONSENSUS Trial Study Group. Effects of enalapril on mortality in severe congestive heart failure: Results of the Cooperative 
North Scandinavian Enalapril Survival Study (CONSENSUS). N Engl J Med 1987; 316: 1429-1435.

49. Vermes E, Tardif JC, Bourassa MG, Racine N, Levesque S, White $\mathrm{M}$, et al. Enalapril decreases the incidence of atrial fibrillation in patients with left ventricular dysfunction: Insight from the Studies Of Left Ventricular Dysfunction (SOLVD) trials. Circulation 2003; 107: 2926-2931.

50. L'Allier PL, Ducharme A, Keller PF, Yu H, Guertin MC, Tardif JC. Angiotensin-converting enzyme inhibition in hypertensive patients is associated with a reduction in the occurrence of atrial fibrillation. J Am Coll Cardiol 2004; 44: 159-164.

51. Wachtell K, Lehto M, Gerdts E, Olsen MH, Hornestam B, Dahlof B, et al. Angiotensin II receptor blockade reduces new-onset atrial fibrillation and subsequent stroke compared to atenolol: The Losartan Intervention For End Point Reduction in Hypertension (LIFE) study. J Am Coll Cardiol 2005; 45: 712-719.

52. Maggioni AP, Latini R, Carson PE, Singh SN, Barlera S, Glazer R, et al. Valsartan reduces the incidence of atrial fibrillation in patients with heart failure: Results from the Valsartan Heart Failure Trial
(Val-HeFT). Am Heart J 2005; 149: 548-557.

53. Murray KT, Rottman JN, Arbogast PG, Shemanski L, Primm RK, Campbell WB, et al. Inhibition of angiotensin II signaling and recurrence of atrial fibrillation in AFFIRM. Heart Rhythm 2004; 1: 669675.

54. Van Den Berg MP, Crijns HJ, Van Veldhuisen DJ, Griep N, De Kam PJ, Lie KI. Effects of lisinopril in patients with heart failure and chronic atrial fibrillation. J Card Fail 1995; 1: 355-363.

55. Madrid AH, Bueno MG, Rebollo JM, Marin I, Pena G, Bernal E, et al. Use of irbesartan to maintain sinus rhythm in patients with longlasting persistent atrial fibrillation: A prospective and randomized study. Circulation 2002; 106: 331-336.

56. Ueng KC, Tsai TP, Yu WC, Tsai CF, Lin MC, Chan KC, et al. Use of enalapril to facilitate sinus rhythm maintenance after external cardioversion of long-standing persistent atrial fibrillation: Results of a prospective and controlled study. Eur Heart J 2003; 24: 2090-2098.

57. Zaman AG, Kearney MT, Schecter C, Worthley SG, Nolan J. Angiotensin-converting enzyme inhibitors as adjunctive therapy in patients with persistent atrial fibrillation. Am Heart J 2004; 147: 823-827. 